\title{
Cytochrome P450 3A4 and 2D6-Mediated Metabolism of Leisure and Medicinal Teas
}

\author{
Teresa W. Tam, ${ }^{1,2}$ Rui Liu, ${ }^{1,2}$ Ammar Saleem, ${ }^{2}$ John Thor Arnason, ${ }^{2}$ Anthony Krantis,,${ }^{1,2}$ and Brian C. Foster ${ }^{1,2,3}$ \\ ${ }^{1}$ Department of Cellular and Molecular Medicine, University of Ottawa, Ottawa, ON, Canada. \\ ${ }^{2}$ Centre for Research in Biopharmaceuticals and Biotechnology, University of Ottawa, Ottawa, ON, Canada. \\ 3 Therapeutic Products Directorate, Health Canada, Ottawa, ON, Canada.
}

Received May 15, 2014; Accepted, July 12, 2014; Published, July 13 ${ }^{\text {th }} 2014$.

\begin{abstract}
PURPOSE: Thirty-five commercially available Camellia sinensis (black and green) and herbal leisure teas and an assortment of Traditional Chinese medicinal teas were randomly selected and examined for their potential to inhibit the drug metabolizing enzyme cytochrome P450 3A4 (CYP3A4). The study was then extended to examine CYP2D6*1 and CYP2D6*10. METHODS: Microtiter fluorometric assays were utilized to examine the potential for the teas to inhibit CYP-mediated metabolism. Aqueous or alcoholic extracts of the dried tea plant material were examined. METHODS: Most of the black and green leisure teas generally inhibited CYP3A4 more than the Chinese medicinal teas. The medicinal Chinese teas were generally more inhibitory towards CYP3A4 compared to the CYP2D6 isozymes, and the aqueous extracts displayed more potency than the alcoholic extracts. CONCLUSIONS: Tea whether used for leisure or medicinal purposes has the potential to inhibit CYP3A4-mediated drug metabolism particularly black tea.
\end{abstract}

This article is open to POST-PUBLICATION REVIEW. Registered readers (see "For Readers") may comment by clicking on ABSTRACT on the issue's contents page.

\section{INTRODUCTION}

Tea next to water is the second most consumed beverage in the world and has been consumed for thousands of years for their alluring flavors and health benefits; however their potential affect on the safety and efficacy of medicinal compounds has not been adequately established $(1,2)$. Peng et al, (3) found that Camellia sinensis extract weakened the effect of $\beta$-lactam antibiotics. In vitro studies showed that the minimal inhibitory concentration of ampicillin, cefazolin, amoxicillin, and oxacillin were greatly decreased by $0.25 \%$ tea extract. In vivo findings showed that $5 \%$ tea extract with amoxicillin conferred a higher median efficacy dose $\left(E D_{50}\right)$ than with antibiotic alone. Several studies have demonstrated either antagonistic or synergistic interactions between tea substances and drugs (4-7). Numerous cultures across the world drink a leisure or medicinal tea as an infusion or tisane or as a decoction prepared by boiling in water. With the broader understanding that botanicals contain a wide range of substances including the anti-oxidant flavonoids the demarcation between what is a leisure and medicinal product has softened and many teas are now being used as both.
Most teas are concoctions of various herbal materials but single-entity products are available. All 6 varieties of teas (white, yellow, green, oolong, black, and pu-erh) are derived from C. sinensis (L) Kuntze but differ in their processing which include steps such as drying steaming or fermentation (2). Processing of green tea includes steaming or frying which inactivates the oxidase and peroxidase and prevents fermentation from occurring. The antioxidant and anticarcinogenic properties of green teas has been attributed to its higher levels of catechins particularly (-)-epigallocatechin gallate (EGCG) (2). The main difference between black and green teas is that black teas are fermented. Oolong oxidation ranges from $10 \%$ to $70 \%$ oxidation somewhere between green and black. The fermentation process utilizes endogenous polyphenol oxidase and peroxidase to catalyze the transformation of catechins to theaflavins, thearubigins, and other compounds, which are responsible for the colour and flavour of black tea (2).

Corresponding Author at: Brian C Foster, Ph.D. Department of Cellular and Molecular Medicine, University of Ottawa, Ottawa, ON, Canada; Email: bfoste2@uottawa.ca 
The total catechin content in green tea is $35 \%$ to $50 \%$ whereas in black tea it ranges at approximately $10 \%$ to $12 \%$ (2). In addition to polyphenols, green tea contains carotenoids; tocopherols; ascorbic acid (vitamin C); minerals such as chromium manganese selenium or zinc; and other phytochemical compounds. Green teas also contain 2 caffeine metabolites: theophylline which is a stronger stimulant than caffeine, and theobromine which is slightly weaker than caffeine. Black tea is generally stronger in flavor and contains more caffeine than the less oxidized teas. Green tea is considered to be a more potent antioxidant than black tea although black tea has substances which green tea does not such as theaflavin. The amount of caffeine and other phytochemical compounds in any single serving of tea varies significantly depending on variety and how the infusion is prepared.

Herbal teas are tisanes and are typically are composed of dried plant material such as flowers, leaves, roots, or rinds. Many Traditional Chinese Medicines (TCMs) are prepared as aqueous decoctions with some containing up to 30 herbs (8).

A wide range of constituents including polyphenols such as catechins and flavonoids which are also present in teas, have been shown to have anti-oxidant, anti-cancer, anti-diabetes, antiinflammatory, anti-hypertensive, or anticarcinogenic properties in vitro and in vivo (9-15). Recent studies have demonstrated that some of these compounds can interact with conventional and alternative medicines (16-22). The potential effect of some teas to mediate serious adverse events may be under estimated as they also contain furanocoumarin derivatives such as bergapten which can elicit mechanism-based inactivation of the major human drug metabolizing enzyme as seen with grapefruit juice (23).

This study was undertaken to determine whether different types of teas have the capacity to affect cytochrome P450 3A4-mediated biotransformation of a marker substance in an in vitro system which would provide mechanistic information that could be related to a patient (24). CYP3A4 is the major human drug metabolizing enzyme of large diverse lipophilic substances (2528 ). Studies were extended to examine the potential of the TCM products to affect CYP2D6*1- and *10-mediated metabolism of a marker substance as the $2 \mathrm{D} 6 * 10$ polymorphism is common within Chinese populations $(23,29)$. CYP2D6 is selective for basic nitrogen ionized hydrophobic substances.

\section{MATERIALS AND METHODS}

\section{Chemicals and reagents}

Aminoethyl-7-methoxy-4-methyl coumarin (AMMC), dibenzylfluorescein (DBF) and microsomes derived from Baculovirus infected insect cells expressing CYP3A4 and CYP-reductase were purchased from BD Biosciences (Mississauga ON Canada). Nicotinamide adenine dinucleotide phosphate reduced form (NADPH), quinidine and azamulin were purchased from Sigma-Aldrich (Oakville ON Canada). Ketoconazole was purchased from Calbiochem (Gibbstown NJ USA). Black, green and herbal teas were randomly selected from different commercial outlets. Medicinal TCM tea sachets were randomly selected by a local Chinese herbalist. Voucher specimens were deposited at the University of Ottawa herbarium. A list of the teas examined is provided in Table 1.

\section{Aqueous sample preparation}

A representative sample of each tea was ground to a fine consistency using a mortar and pestle. The TCM material did not require any processing as the material was provided in the sachets in a usable ground form. Water and alcohol (methanol or ethanol) extracts were prepared by vigorously vortexing $25 \mathrm{mg}$ of ground material in $1 \mathrm{ml}$ of the solvent for $1 \mathrm{~min}$. The extract was separated from the undissolved material by centrifugation for 15 $\mathrm{min}$ at $1000 \mathrm{xg}$ at room temperature.

\section{CYP inhibition assay}

The assays were performed in triplicate in 96-well plates with white walls and clear flat bottoms under red-colored light to minimize the exposure of fluorescent light to photosensitive material using a previously described method $(20,30)$. In brief, the fluorescence was measured using a Cytofluor 4000 Fluorescence Measurement System (Applied Biosystems Foster City CA) using active and inactivated enzyme. For CYP3A4, a volume of 10 $\mu 1$ of the tea extract, $10 \mathrm{nM}$ CYP3A4, $1 \mu \mathrm{M}$ DBF (dissolved in acetonitrile), and $0.6 \mathrm{mM} \mathrm{NADPH}$, were incubated in $0.19 \mathrm{M}$ phosphate buffer solution (buffer $\mathrm{pH}$ 74) at a final volume of $200 \mu \mathrm{l}$ for 20 min. The initial and final fluorescence was read at $485 \mathrm{~nm}$ excitation and $530 \mathrm{~nm}$ emission with a gain of 50. For ethanol extracts the extract was diluted ten-fold prior to testing. The positive inhibitor used 
was $19 \mu \mathrm{M}$ ketoconazole (dissolved in $\mathrm{MeOH}$ ). A similar method to the CYP3A4 inhibition assay was used for CYP2D6*1 and *10 except $10 \mathrm{nM}$ CYP2D6*1 or *10, $0.12 \mu \mathrm{M}$ AMMC (dissolved in acetonitrile), and $0.2 \mathrm{mM}$ NADPH was used. The initial and final fluorescence was read at $409 \mathrm{~nm}$ excitation and $460 \mathrm{~nm}$ emission with a gain of 85 and an incubation time of $40 \mathrm{~min}$. The positive inhibitor used was $2 \mu \mathrm{M}$ quinidine (dissolved in $\mathrm{MeOH}$ ). Initial fluorescence was subtracted from respective final fluorescence for the calculations. The percent inhibition of each extract was calculated relative to the CYP activity with the vehicle control.

\begin{tabular}{|c|c|c|}
\hline NRP \# & Name & Label contents and product description \\
\hline 420 & Afternoon Blend & China Darjeeling and Ceylon teas \\
\hline 386 & Awake Black Tea & Blend of black teas \\
\hline 417 & Black Tea Decaffeinated & Decaffeinated China Indian and Ceylon black teas \\
\hline 387 & Calm Herbal Infusion & $\begin{array}{l}\text { Chamomile flowers, hibiscus flowers, spearmint, lemongrass, rose petals, } \\
\text { blackberry leaves, safflowers, peppermint, sarsaparilla, lemon balm, licorice, } \\
\text { natural flavours }\end{array}$ \\
\hline 418 & Ceylon Tea & Black tea \\
\hline 424 & Chamomile and Apple Herbal & Chamomile, natural flavours, ginger, cinnamon, apple pieces \\
\hline 438 & Chamomile Court & Chamomile, orange peel, rose hips, hibiscus flowers and allspice \\
\hline 435 & Cozy Chamomile Herb Tea & Chamomile \\
\hline 416 & Darjeeling Tea & Black tea \\
\hline 425 & Darjeeling Tea & Black tea \\
\hline 388 & Earl Grey Black Tea & Black teas blended with the essence of bergamot \\
\hline 429 & English Breakfast & Blend of black teas \\
\hline 421 & Golden Jubilee Tea & Darjeeling, Keemun and Ceylon teas \\
\hline 389 & Green Ginger Green Tea & Green teas, natural flavours, ginger, lemongrass \\
\hline 436 & Green Tea with Lemon & Green tea, lemon peel, natural flavor \\
\hline 430 & Gunpowder Green & Green tea \\
\hline 434 & Jasmine Tea & Green tea scented with fresh Jasmine flowers \\
\hline 427 & Keemun & Black tea \\
\hline 428 & Lady Grey & Variation of Earl Grey tea made with lemon and orange peel \\
\hline 433 & Lapsang Souchong & Black Tea \\
\hline 423 & Lemon and Ginger Herbal Tea & $\begin{array}{l}\text { Ginger root, natural flavours, linden, lemon peel, blackberry leaves, lemon } \\
\text { grass, citric acid }\end{array}$ \\
\hline 439 & Lemon Lane & $\begin{array}{l}\text { Lemon peel, orange peel, hibiscus flowers, rosehips, lemon grass, and } \\
\text { roasted chicory root }\end{array}$ \\
\hline 437 & Mint Soother & Potpourri of soothing herbs including chamomile and mint \\
\hline 432 & No 22 & Blend of black teas \\
\hline 390 & Organic Chai Spiced Black Tea & Black teas, ginger, cinnamon, black pepper, cardamom, cloves, star anise \\
\hline 391 & Passion Herbal Infusion & $\begin{array}{l}\text { Hibiscus flowers, natural tropical flavours, citric acid, orange peel, licorice } \\
\text { root, cinnamon, rose hips, lemongrass, fruit juice extract }\end{array}$ \\
\hline 422 & Prince Charles & Blend of black teas \\
\hline 419 & Queen Victoria & Blend of 9 select green and black teas \\
\hline 415 & Russian Caravan & Oolong, Keemun and Lapsang Souchong teas \\
\hline 426 & South African Kwazula & Black tea \\
\hline 392 & $\begin{array}{l}\text { Wild Sweet Orange Herbal } \\
\text { Infusion }\end{array}$ & $\begin{array}{l}\text { Lemongrass, blackberry leaves, citric acid, rose hips, spearmint, natural } \\
\text { flavours, orange peel, safflower, hibiscus flowers, rose petals, natural orange } \\
\text { essence, ginger, licorice root }\end{array}$ \\
\hline 431 & Yunnan & Black tea \\
\hline 393 & Zen Green Tea & Green tea, lemon, verbena, spearmint leaves, lemongrass, natural flavor \\
\hline
\end{tabular}




\section{RESULTS}

The assay system used a series of internal controls to determine which samples if any had constituents capable of quenching the fluorescence. Quenching was not detected in any of the samples under these test conditions. Initial screening determined that all products completely inhibited CYP3A4-mediated metabolism of DBF. Subsequent testing of aqueous black, green, and herbal tea extracts were then undertaken at a single concentration of $25 \mathrm{mg} / \mathrm{ml}$ where most if not all of these products had an inhibitory effect of $95 \%$ or less.

In total, aqueous extracts from 19 different varieties of black tea, 5-selections of green teas, 11 varieties of herbal teas, and aqueous and alcohol extracts of 7 TCMs were tested for their potential to inhibit CYP3A4-mediated metabolism of DBF. These teas were randomly selected from a wider range of teas from several commercial outlets. Several of the teas contained a mixture of herbal and green teas and were grouped with both categories.

The black teas were generally more inhibitory than the green and herbal teas with 12 of the 19 black teas inhibiting more than $75 \%$ of the CYP3A4 activity relative to a vehicle control (Figure 1). Only 2 black tea extracts, NRP427 and 433, had weak inhibition towards CYP3A4 inhibiting less than $10 \%$ of CYP3A4 activity. Herbal tea extracts were generally the least inhibitory towards CYP3A4 activity which ranged from $-4.3 \pm 16 \%$ to $60.8 \pm 30 \%$ inhibition. Four of the herbal teas NRP391, 435, 437, and 438 had weak inhibition towards CYP3A4 activity. Many of the herbal teas which had a weak or moderate CYP3A4 inhibition had a common main ingredient of chamomile. Green tea extracts were generally less inhibitory than those from black teas but more inhibitory than the herbal teas. All of the green teas examined effected greater than $45 \%$ inhibition of CYP3A4 activity and 3 of the 5 green teas (NRP389, 430, and 434) had greater than $75 \%$ inhibition of CYP3A4 activity.

Seven different TCMs (NRP 265 to 271) were examined for their capacity to inhibit CYP3A4mediated metabolism (Table 2). TCM material was randomly selected by a Chinese herbalist who made an a priori decision to provide products that were both readily available and in sachets in a usable extract or ground form. At a concentration of 25 $\mathrm{mg} / \mathrm{ml}$ the water extracts were more potent
CYP3A4 inhibitors than the alcohol extracts except for NRP270 and 271 (Table 3). Methanolic extracts from these 2 TCMs inhibited approximately $71 \%$ of CYP3A4 activity. Four of the water extracts from NRP265, 266, 268, and 269 inhibited at least 75\% of CYP3A4 activity. The Chinese medicinal tea extracts uniformly had a high inhibitory effect on 3A4-mediated metabolism.

Testing of NRP 265 to 271 was then extended to examined their capacity to inhibit CYP2D6*1and 2D6*10-mediated metabolism. Less inhibition was observed against CYP2D6*1 and *10 activity for both the TCM water and alcohol extracts at 25 $\mathrm{mg} / \mathrm{ml}$. For most of the TCMs similar inhibition against CYP2D6*1 activity was observed for both aqueous and ethanolic extracts. NRP265 was the most inhibitory TCM inhibiting $64.3 \% \pm 4.4 \%$ and $62.3 \% \pm 7.3 \%$ of CYP2D6*1 activity for the aqueous and ethanolic extracts respectively. All of the other TCM extracts inhibited CYP2D6*1 activity with less than $40 \%$ relative to the vehicle control and several of these TCMs (NRP267, 268, and 271) inhibited less than $10 \%$ of CYP2D6*1 activity.

Similar results were obtained with CYP2D6*10. Aqueous and ethanolic extracts of the TCMs had similar inhibition towards CYP2D6*10 and NRP265 was the most inhibitory TCM inhibiting $57.8 \% \pm 6.2 \%$ and $71.3 \% \pm 3.7 \%$ of CYP2D6*10 activity for the aqueous and ethanolic extracts, respectively. All of the other TCM extracts inhibited CYP2D6*10 activity with less than $40 \%$ relative to the vehicle control.

\section{DISCUSSION}

As may be expected for complex products, there was no clear demarcation between the leisure teas examined. This may relate to the limited number of products tested, minor differences in particle size, and other harvesting and manufacturing processes. The findings revealed that for the leisure teas there was a grouping with high $(>75 \%)$, moderate ( 25 to $75 \%)$, and low $(<25 \%)$ inhibitory potential to affect CYP-mediated metabolism. Within these products the green teas tended to be slightly less inhibitory than black teas towards CYP3A4-mediated metabolism. Overall the herbal teas tended to have a similar or lower inhibitory potential than the green teas. 


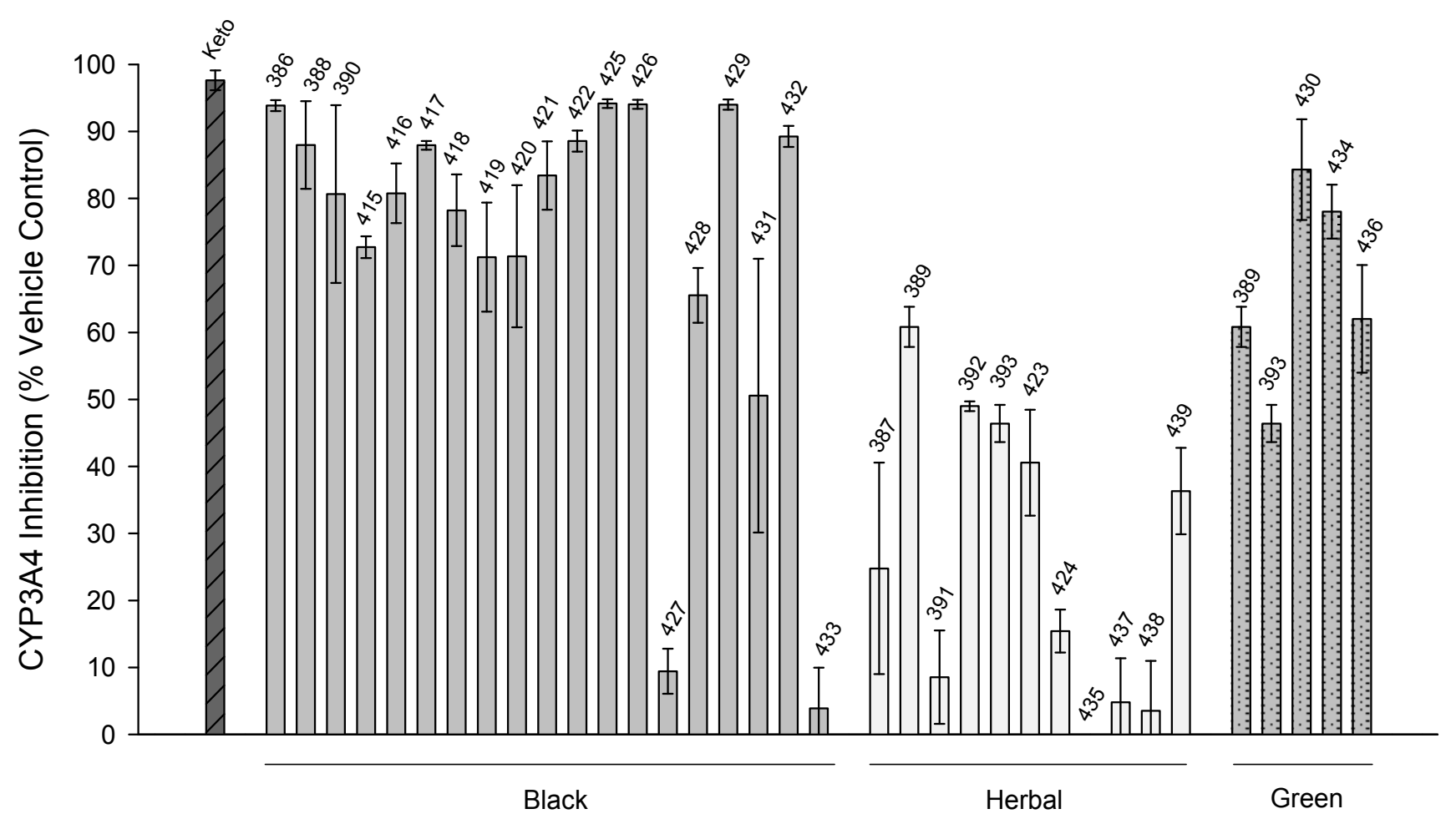

NRP Number

Figure 1. Inhibition of human cytochrome P450 3A4 mediated-metabolism by aliquots of various black herbal and green teas (each replicate of 3 was repeated 2-3 times; mean \pm SEM). A volume of $10 \mu 1 \mathrm{of} 5 \mathrm{mg} / \mathrm{ml}$ aqueous extracts was examined. Ketoconazole (Keto $19 \mu \mathrm{M}$ ) was used as a positive control. NRP, Nutraceutical Research Programme number.

\begin{tabular}{|c|c|c|}
\hline NRP \# & Name & Label contents and product description \\
\hline 269 & $\begin{array}{l}\text { Chai Hu (Radix Bupleuri), } \\
\text { China, 柴胡 }\end{array}$ & $\begin{array}{l}\text { common cold fever cough, infectious hepatitis, liver cirrhosis, erythema and } \\
\text { globus hystericus }\end{array}$ \\
\hline 265 & $\begin{array}{l}\text { Chrysanthemum Flower (Flos } \\
\text { Chrysanthemi), China, 菊花 }\end{array}$ & anti-inflammatory or antimicrobial prevent cardiopathy \\
\hline 268 & $\begin{array}{l}\text { Du Huo (Radix Angelicae } \\
\text { Pubescentis), China, 独活 }\end{array}$ & \\
\hline 270 & $\begin{array}{l}\text { Indian Bread with Hostwood } \\
\text { (Sclerotium Poriae Circum } \\
\text { Radicem Pini), China, 获神 }\end{array}$ & ataractic \\
\hline 267 & $\begin{array}{l}\text { Isatis Root (Radix Isatidis), } \\
\text { China, 板蓝根 }\end{array}$ & anti-fever detoxification; against virulent cold swollen pharynx and larynx \\
\hline 266 & $\begin{array}{l}\text { Kudzuvine Root (Radix } \\
\text { Puerariae), China, 葛根 }\end{array}$ & $\begin{array}{l}\text { anti-fever spasmolysis, reduce blood sugar, treat hypertension, apoplexy, } \\
\text { and coronary heart disease }\end{array}$ \\
\hline 271 & $\begin{array}{l}\text { Tangshen (Radix Codonopsis), } \\
\text { China, 党参 }\end{array}$ & $\begin{array}{l}\text { enhance the immune system, hematopoietic function, improve the function } \\
\text { of blood circulation system; anti-ulceration sedation and improve memory }\end{array}$ \\
\hline
\end{tabular}


Table 3. Inhibition of human cytochrome P450 2D6*1 2D6*10 and 3A4 by aliquots of various aqueous and alcohol Traditional Chinese Medicine tea extracts $(10 \mu \mathrm{l}$ of $25 \mathrm{mg} / \mathrm{ml} ; \mathrm{n}=2-3$; mean \pm SEM).

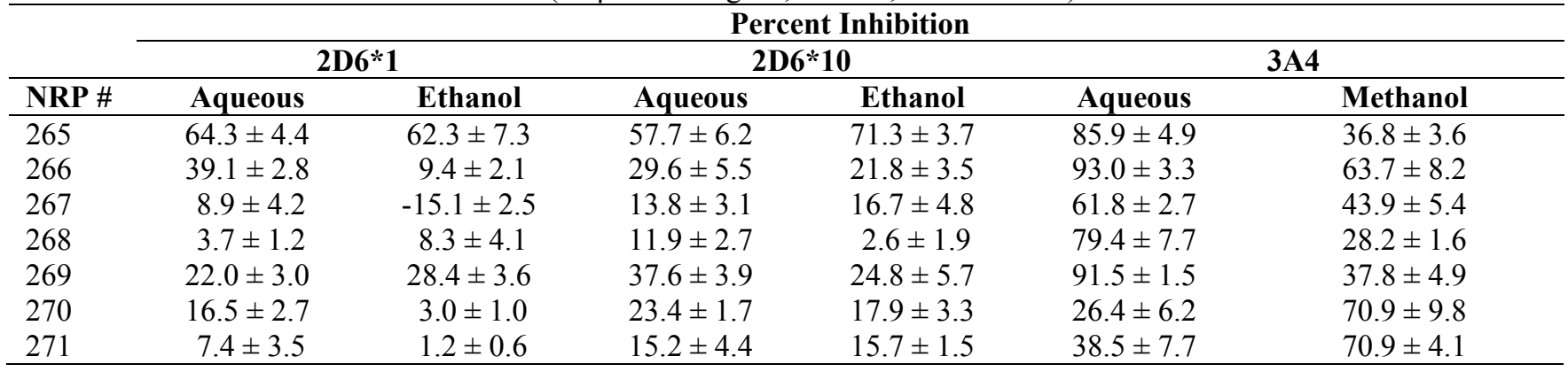

As many Asians have the 2D6*10 polymorphism which reduces the activity of this enzyme it was of interest to determine if these teas may affect this isoform. It was noteworthy that there were some differences in response with the $2 \mathrm{D} 6 * 1$ and $* 10$ isoforms; the differences would not be expected to have a clinically important effect.

Extrapolation of in vitro findings to a clinical situation can be confounded by many intrinsic and extrinsic factors; however an in vitro determination of mechanism for an interaction is valuable in demonstrating the relative importance of a pathway (24). As there can be substantial variation in the composition of botanical products due to several factors including environmental conditions, time and year of harvest, and the manufacturing and storage processes, there may be multiple pharmacologically active substances affecting one or more pathways that can affect bioavailability and hence, pharmacodynamic activity $(2,31,32)$. The complex nature of botanicals can effectively preclude unequivocal association of a pharmacological effect to a single substance.

Teas have long been safely consumed by many cultures for both leisure and their medicinal benefits. As accessibility and understanding of the mechanistic basis for improved health benefits of these products grow, new formulations and uses are being reported. However, there still remains insufficient information on whether the traditional or newer products may present risk when used concomitantly with other health products. This study has provided mechanistic information to assess any potential risk of these products to interact with other products metabolized by these isozymes. Although actual risk of a serious adverse event resulting from an interaction will depend on intrinsic and extrinsic factors including dose and rate of ingestion, these findings demonstrate that there is a mechanistic-basis for tea-mediated interactions with other health products metabolized by these isozymes.

The findings of this study with a wide random selection of leisure medicinal and traditional teas are significant in that they provide mechanistic support that some of these products have the potential to affect the safety and efficacy of other health and medicinal products. Variation in risk between similar products is expected and the findings with these samples cannot be directly extrapolated to other lots or similar products. As this study only examined two of the important human metabolic enzymes (CYP2D6 and CYP3A4) it is possible that teas contain additional substances that could also be affect other metabolic enzymes. This uncertainty warrants further investigation. In particular, white, yellow, oolong and pu-erh teas should be examined for their potential to affect drug metabolism.

\section{ACKNOWLEDGEMENTS}

Funding was provided in part by the Therapeutic Products Directorate, Health Canada.

\section{CONFLICT OF INTEREST}

The authors have declared that there is no conflict of interest.

\section{REFERENCES}

1. Higdon JV, Frei B. Tea catechins and polyphenols: Health effects metabolism and antioxidant functions. Crit Rev Food Sci Nutr, 2003; 43:89-143.

2. Ho C, Lin J, and Shahidi F. Tea and Tea Products: Chemistry and Health-Promoting Properties Taylor and Francis Group Boca Raton FL, 2009. 
3. Peng Q, Huang Y, Hou B, Hua D, Yao F, Qian Y. Green tea extract weakens the antibacterial effect of amoxicillin in methicillin-resistant Staphylococcus aureus infected mice. Phytother Res, 2010; 24(1):141-145.

4. Chen L, Ye HL, Zhang G, Yao WM, Chen XZ, Zhang FC, Liang G. Autophagy Inhibition Contributes to the Synergistic Interaction between EGCG and Doxorubicin to Kill the Hepatoma Hep3B Cells. PLoS One, 2014; 9(1):e85771.

5. Jia L, Liu FT. Why bortezomib cannot go with 'green'? Can Biol Med, 2013; 10(4):206-213.

6. Lu Y, Sun J, Petrova K, Yang X, Greenhaw J, Salminen WF, Beger RD, Schnackenberg LK. Metabolomics evaluation of the effects of green tea extract on acetaminophen-induced hepatotoxicity in mice. Food Chem Tox, 2013; 62:707-721.

7. Navarro VJ, Bonkovsky HL, Hwang SI, Vega M, Barnhart H, Serrano J. Catechins in dietary supplements and hepatotoxicity. Dig Dis Sci, 2013; 58(9):2682-2690.

8. Chan K. Chinese medicinal materials and their interface with western medical concepts. J Ethnopharmacol, 2005; 96:1-18.

9. Katiyar SK, Bergamo BM, Vyalil PK, Elmets CA. Green tea polyphenols: DNA photodamage and photoimmunology. J Photochem Photobiol B, 2001; 65:109-114.

10. Kris-Etherton PM, Keen CL. Evidence that the antioxidant flavonoids in tea and cocoa are beneficial for cardiovascular health. Curr Opin Lipidol, 2002; 13:41-49

11. Mukhtar H, Ahmad N. Tea polyphenols: Prevention of cancer and optimizing health. Am J Clin Nutr, 2000; 71(6S):1698S-1704S.

12. Riemersma RA, Rice-Evans CA, Tyrrell RM, Clifford MN, Lean MEJ. Tea flavonoids and cardiovascular health. QJM - J Assoc Physic, 2001; 94:277-282.

13. Rimm EB, Katan MB, Ascherio A, Stampfer MJ, Willett WC. Relation between intake of flavonoids and risk for coronary heart disease in male health professionals. Ann Int Med, 1996; 125:384-389.

14. McCune LM, Johns T. Antioxidant activity in medicinal plants associated with the symptoms of diabetes mellitus used by the Indigenous Peoples of the North American boreal forest. J Ethnopharmacol, 2002; 82:197-205.

15. Vinson JA, Dabbagh YA, Serry MM, Jang J. Plant flavonoids especially tea flavonols are powerful antioxidants using an in vitro oxidation model for heart disease. J Agri Food Chem, 1995; 43:28002802.

16. Foster BC, Vandenhoek S, Hana J, Krantis A, Akhtar MH, Bryan M, Budzinski JW, Ramputh A, Arnason JT. In vitro inhibition of human cytochrome P450-mediated metabolism of marker substrates by natural products. Phytomed, 2003; 10:334-342.

17. Huang S-M, Leshko LJ. Drug-drug drug-dietary supplement and drug-citrus fruit and other food interactions: what have we learned? J Clin Pharmacol, 2004; 44:559-569.

18. Marchetti S, Mazzanti R, Beijnen JH, and Schellens JHM. Concise review: Clinical relevance of drugdrug and herb-drug interactions mediated by the $\mathrm{ABC}$ transporter $\mathrm{ABCB} 1$ (MDR1 P-glycoprotein). Oncolog, 2007; 12:927-941.

19. Nowack R. Review article: Cytochrome P450 enzyme and transport protein mediated herb-drug interactions in renal transplant patients: Grapefruit juice St John's wort - and beyond! Nephrol, 2008; 13:337-347.

20. Tam TW, Liu R, Arnason JT, Krantis A, Staines WA, Haddad PS, Foster BC. Actions of ethnobotanically selected Cree anti-diabetic plants on human cytochrome P450 isoforms and flavincontaining monooxygenase 3. J Ethnopharmacol, 2009; 126:119-126.

21. Tam TW, Liu R, Arnason JT, Krantis A, Staines WA, Haddad PS, Foster BC. Cree anti-diabetic plant extracts display mechanism-based inhibition of CYP3A4. Can J Physiol Pharmacol, 2011; 89(1):1323.

22. Zhou S, Gao Y, Jiang W, Huang M, Xu A, Paxton JP. Interactions of herbs with cytochrome P450. Drug Met Rev, 2003; 35:35-98.

23. Meyer UA, Zanger UM. Molecular mechanisms of genetic polymorphisms of drug metabolism. Annu Rev Pharmacol Toxicol, 1997; 37:269-296.

24. US FDA Guidance for Industry In Vivo Drug Metabolism/Drug Interaction Studies — Study Design Data Analysis and Recommendations for Dosing and Labeling November 1999

25. Anzenbacher P, Anzenbacherová E. Cytochromes P450 and metabolism of xenobiotics. Cell Molec Life Sci, 2001; 58:737-747.

26. Daly AK. Pharmacogenetics of the cytochromes P450. Curr Top Med Chem, 2004: 4(16):1733-1744.

27. Furge LL, Guengerich FP. Cytochrome P450 enzymes in drug metabolism and chemical toxicology: An introduction. Biochem Molec Biol Educ, 2006; 34:66-74.

28. Lewis DF. 57 varieties: the human cytochromes P450. Pharmacogenomics 2004: 5(3):305-318.

29. Daly AK. Significance of the minor cytochrome P450 3A isoforms. Clin Pharmacokinet, 2006; 45(1):13-31.

30. Foster B C, Foster M S, Vandenhoek S, Krantis A, Budzinski J W, Arnason $\mathrm{J} \mathrm{T}$, et al. An in vitro evaluation of human cytochrome P450 3A4 and Pglycoprotein inhibition by garlic. J Pharm Pharmaceut Sci, 2001; 4:176-184. 
31. Cordero C, Canale F, Del Rio D, Bicchi C. Identification quantitation and method validation for flavan-3-ols in fermented ready-to-drink teas from the Italian market using HPLC-UV/DAD and LCMS/MS. J Sep Sci, 2009; 32(21):3643-3651.

32. Erturk Y, Ercisli S, Sengul M, Eser Z, Haznedar A, Turan M. Seasonal variation of total phenolic antioxidant activity and minerals in fresh tea shoots (Camellia sinensis var sinensis). Pak J Pharm Sci, 2010; 23(1):69-74. 